Original Article

\title{
EVALUATION OF EFFECT OF REUSED EDIBLE OILS ON VITAL ORGANS OF WISTAR RATS
}

\author{
Shastry C.S., Patel Narendrakumar Ambalal, Joshi Himanshu \& Aswathanarayana B.J. \\ Department of Pharmacology, NGSM Institute of Pharmaceutical Sciences, \\ Deralakatte, Mangalore - 575 018, India. \\ Correspondence : \\ Shastry C.S., \\ Department of Pharmacology, NGSM Institute of Pharmaceutical Sciences, \\ Nitte University, Mangalore - 575018 \\ E-mail : principal.ngsnips@ nitte.edu.in
}

\begin{abstract}
:
Objectives : Cooking oils (edible oils) are vegetable oils which are extensively used for cooking in India. These edible oils are rich in triglycerides, sterol, tocoferol, carotenes and pigments. Upon frying, edible oils gives rise to formation of free radicals and other harmful agents. The degraded products of oils generated while cooking produce unfavorable effects. The present study was designed to evaluate the effects of reused edible oils (sunflower oil and palm oil) on vital organ s of experimental animals.
\end{abstract}

Materials and Methods : Wistar rats were fed fresh and reused edible oils - sunflower oil and palm oil (15 gm oil/ 100gm of feed consumed) and control group received normal food and water for a period of 8 weeks. The parameters studied include changes in physicochemical properties of reused oils, change in body weight of animals, plasma lipid profile, biochemical parameters and histopathological examination.

Results: The result showed the change in physicochemical characteristics of reused oils. The animals fed with fresh and reused palm oil significant increase the body weight while reused sunflower oil fed group showed decrease significantly. The biochemical parameters, SGPT (serum glutamate - pyruvate transaminase), SGOT (serum glutamate- oxaloacetate transaminase), and ALP (alkaline phoshphatase) were increased in reused oils fed groups. The histopathological study showed the change in size of liver, heart, kidney and testes cellsin reused oil groups.

Conclusions: From the present study, it can be concluded that reused sunflower oil and palm oil, can be toxic and can cause considerable damage to the vital organs of the experimental animals.

Keywords: Edible oils, sunflower oil, palm oil, free radicals.

\section{Introduction:}

Increasingly, over the past 40 years, the conception of diet has undergone major changes. Many of these changes involve changes in dietary intake of fats and oils [1]. Cooking oil are vegetable oils, which are obtained from coconut, ground nut, sunflower seeds, palm, cottonseeds etc, are extensively used in the preparation of diet. These fats and oils are the esters of glycerol and various straight chained mono carboxylic acids, known as fatty acids. These fatty acids may be saturated, monosaturated or poly unsaturated [2]. Consumption of foods, which have been subjected repeatedly to deep-frying using various edible oils, is a common feature in India, although the type and composition of edible oil commonly used for cooking and frying in the Indian kitchens vary greatly from region to region. These used cooking oils constitute a waste generated from activities in the food sector (industries and restaurants), which has greatly increased in recent years. The main use of reused oil at present is in animal feed and in a much smaller proportion in the manufacture of soaps, biodegradable lubricants or for combustion (recovery of energy in industrial plants). As a consequence, the use of recycled cooking oils in animal feed must be studied from the point of view of safety as the fats and oils which are heated at high temperature during deep frying ( which is a popular food preparation method in India) which may generates high levels of cytotoxic products. It may promote the induction, development and progression of cardiovascular diseases [3].

Moreover, heating of oil produces various peroxidative changes. Peroxidation of biological systems is regarded to 
be associated with a number of pathological manifestations. Effects of various types of dietary fats including vegetable oils on plasma lipid and lipoprotein concentrations and the influence of their constituents fatty acids on incidence of coronary heart disease have been reported [4].

To best of our knowledge no scientific data regarding the effect of reused edible oil on vital organs of albino rats. Hence we have undertaken the present study to evaluate the effect of reused sunflower oil and palm oil on the vital organs of rats by assessing the body weight of animals, plasma lipids profile, biochemical parameters and histopathological examination.

\section{Materials and methods:}

\section{Chemicals:}

Bio-Chemical Kits for the estimation of SGOT, SGPT, ALP, Total protein, Total Cholesterol, Triglyceride, HDL, Glucose, Serum albumin, Blood urea nitrogen, Creatinine, and Bilirubin were procured from Agape Diagnostics Ltd, Kerala, India. Potassium dihydrogen phosphate and formalin, were procured by HighMedia, Bombay, India. And all other chemicals were of analytical grade and used as received.

\section{Sample oils:}

The fresh sunflower and palm oils were purchased from local market and directly used for animal feeding. Reused Palm oil and sunflower oil were collected from the fast food joints and restaurants located in and around the Mangalore. (Recycled for 6 to 8 times). The physicochemical characteristics of oils were determined according to the standard procedure after procurement [2, 5].

\section{Animals:}

All the experiments were carried out with Wistar rats of either sex weighing 200-250g. Animals were kept in the animal house of NGSM Institute of Pharmaceutical Sciences, Deralakatte, Mangalore under controlled conditions of temperature $(23 \pm 2 \circ \mathrm{C})$, humidity $(50 \pm 5 \%)$ and $12 \mathrm{~h}$ light-dark cycle. Animals were fed standard pellet diet and water ad libitum. All the animals were acclimatized for seven days before the study.

Approval from the Institutional Animal Ethical Committee (Approval Number: IAEC/030/2004-05) was obtained before the commencement of the studies.

\section{Experimental design :}

The study comprises five groups of 6 animals. Oils were to each group of animals by oral route as under:

Group 1-Control (Normal food and water)

Group2-Fresh palm oil

Group3-Reused palm oil

Group4- Fresh sunflower oil

Group5-Reused sunflower oil

Feed: $15 \mathrm{gm}$ oil/100gm of standard feed Dose: 15 gms/day/rat

The animals were provided food and water ad libitum throughout the experimental period of 8 weeks. Body weights were taken twice a week. Before sacrifice, blood was collected under anesthesia for biochemical analysis. Blood from each animal was collected a test tube without anticoagulant for serum separation. SGOT, SGPT, ALP, Total protein, Total Cholesterol, Triglyceride, HDL, Glucose, Serum albumin, Blood urea nitrogen, Creatinine, and Bilirubin were estimated. The liver, heart, kidneys, spleen and testes were weighed and were taken for histopathological examination [6-8].

\section{Statistical analysis:}

All data were expressed as mean \pm standard error of the mean (S.E.M.) of 6 rats per experimental group. Parametric one way analysis of variance (ANOVA) followed by Dunnet's t-test. Statistical analyses were performed using Graph pad prism 5.0

\section{Results:}

\section{Physicochemical Characteristics of oils:}

Analysis of physicochemical properties of reused oil showed significantly increase in lodine value, Peroxide value, Acid value and Carbonyl value compare to the fresh oils of both palm oil and sunflower oil. (Table 1 )

\section{Changes in body weight:}

The body weights of rats were monitored during the study 
period. The animal fed with fresh palm, sunflower oils and reused palm oil showed significant increase in the body weight during the study period but weight gain in animals fed with fresh sunflower oil was lesser than palm oil fed group. However, the animal fed with reused sun flower oil lost weight significantly. (Table 2)

\section{Analysis of lipid level:}

The lipid profile of animals showed significant increase in cholesterol level in all the groups as compared to control group. Increase in cholesterol level of sunflower oil group treated was lesser compared to palm oil fed group. The reused oil sunflower oil groups showed increase in cholesterol levels compare to its fresh oil group. There was significantly increase in the triglyceride content of reused palm oil and sunflower oil fed group compared to control group as well as to the fresh oil groups. Only fresh palm oil fed group showed slight increase in the HDL level, where as remaining groups did not show any significant changes. The animal fed with reused palm oil, sunflower oil and fresh sunflower oil groups showed significant increase in LDL levels compared to control group. (Table 3)

\section{Biochemical parameters:}

The animal fed with reused oils significantly affects the serum enzymes. The reused oils groups showed significant increase in the levels of SGPT, SGOT and ALP compared to control group. (Table 4)

\section{Histopathological examination :}

The histopathological study showed that the liver cells of reused oils group's were swollen with chronic inflammatory cells infiltration, micro granules were observed near to the portal area. (Figure 1) The histopathology of heart showed congested myocardial and few vacuolation in papillary muscle. (Figure 2 ) The kidney showed tubular cell in medullary region, cytoplasmic as well as nuclear vacuoles. Occasional tubules contained eosinophilic materials in the lumen. (Figure 3) The testis showed fine vacuoles in cytoplasm and in nucleus of germ cells. (Figure 4)

\section{Discussion :}

Used cooking oils constitute wastes generated from activities in the food sector. The process of frying gives rice to the formation free radicals and other harmful agents. Oxidation reaction, hydrolysis of triglycerides and polymerization of triglycerides give rise to peroxides which are the starting point for the formation of several free radicals [9]. Deep-frying of edible oils leads to oxidative degradation of fats and oils. Free-radical initiated oxidation is one of the main causes of rancidity in fats and oils. This results in the alteration of major quality variables such as colour, flavour, aroma and nutritional value [10]. This repeated heating of edible oils also leads to the formation of many toxic substances. Among them, polycyclic aromatic hydrocarbons (PAHs) are well-documented for their mutagenic or carcinogenic potential [11], dioxin contamination (Dioxin is polychlorinated dibenzo-pdioxins and polychlorodibenzo furans, a family of polychlorinated tricyclic aromatic compounds) [9]. Other compounds are triacylglycerol dimers, trimers and other polymers (whose presence may reach up to $30 \%$ of total oil in recycled cooking oils). Cyclic monomers which are formed by intra molecular ring formation of fatty acids, free, or constituting triacylglycerols. These cyclic monomers are present to a lesser extent but they have higher toxicity compared with polymers mainly due to their higher rates of absorption in the body [12]. The thermal stressing of PUFA rich edible oils during routine frying or cooking practices generates high levels of cytotoxic aldehydic products also lead to cardiovascular diseases [3].

During this study we checked the changes in physicochemical characteristics of oils during repeated heating and the effect of recycled edible oils on body weight gain, serum enzymes level, lipid profile and histopathological changes in vital organ of rats.

The analysis of physicochemical properties of reused oil showed the increase in lodine values of reused palm oil and sunflower oil suggesting no significant change on unsaturated fatty acid content of oils after heating. Peroxide value of reused oils is also increased and it was more susceptible to oxidation. Acid value of reused oil was found to be increase due to rancidity. Carbonyl value of reused oil was also found to be high, indicating unsafe for 
consumer health. These changes in physicochemical parameters of reused oils confirm the oxidation of edible oil and formation of free radicals. The increased levels of SGPT, SGOT and ALP in our study suggested the hepatic injury in animals from reused edible oils. The lipid profile study shows increase in cholesterol, triglyceride and LDL levels in the animals treated with reused oils. Increase cholesterol level in reused oil, ingestion of oxidized lipids rich in linoleic acid causes profound alteration in membrane composition fluidity and function. This

Table 1: Physicochemical Characteristics of oils

\begin{tabular}{|l|c|c|c|c|}
\hline Group & Iodine value & $\begin{array}{c}\text { Peroxide value } \\
\text { (meq/ } / \mathrm{kg} \text { of fat) }\end{array}$ & Acid value & Carbonyl value \\
\hline Fresh palm oil & $45 \pm 0.021$ & $3.18 \pm 0.022$ & $1.75 \pm 0.07$ & $4.23 \pm 0.02$ \\
\hline Reused palm oil & $49.10 \pm 0.17$ & $4.85 \pm 0.01$ & $9.80 \pm 0.10$ & $10.41 \pm 0.12$ \\
\hline Fresh sunflower oil & $132 \pm 0.02$ & $6.6 \pm 0.017$ & $1.21 \pm 0.034$ & $10.7 \pm 0.41$ \\
\hline Reused sunflower oil & $145.5 \pm 0.31$ & $17.3 \pm 0.021$ & $7.62 \pm 0.13$ & $25.8 \pm 0.18$ \\
\hline
\end{tabular}

Values are means of 3 readings \pm SEM .

Table 2: Changes in body weight

\begin{tabular}{|l|c|c|c|c|c|}
\hline Groups & Control & $\begin{array}{c}\text { Fresh } \\
\text { palm oil }\end{array}$ & $\begin{array}{c}\text { Reused } \\
\text { palm oil }\end{array}$ & $\begin{array}{c}\text { Fresh } \\
\text { sunflower oil }\end{array}$ & $\begin{array}{c}\text { Reused } \\
\text { sunflower oil }\end{array}$ \\
\hline Initial body wt (g) & $240 \pm 5.80$ & $235 \pm 15.54$ & $240 \pm 23.09$ & $263.37 \pm 8.8$ & $250 \pm 15.27$ \\
\hline Final body wt (g) & $273 \pm 3.3^{\mathrm{c}}$ & $313 \pm 11.08^{\mathrm{a}}$ & $303 \pm 14.52^{\mathrm{a}}$ & $310.0 \pm 10.0^{\mathrm{b}}$ & $206 \pm 12.0$ \\
\hline Weight gain (g) & $33.3 \pm 6.6^{\mathrm{c}}$ & $77.5 \pm 4.78^{\mathrm{a}}$ & $63.33 \pm 8.8^{\mathrm{a}}$ & $46.67 \pm 6.24^{\mathrm{b}}$ & $-44.00 \pm 5.8^{\mathrm{a}}$ \\
\hline
\end{tabular}

Values are mean of 6 animals \pm SEM, $a=p<0.01$ vs initial body weight, $b=p<0.025$ vs initial body weight, $c=p<0.05$ vs initial body weight.

Table 3: Lipid level in rats.

\begin{tabular}{|l|c|c|c|c|c|}
\hline Group & Sex & Total Cholesterol & Triglyceride & HDL & LDL \\
\hline Control & M & $128.78 \pm 2.13$ & $163.31 \pm 4.0$ & $62.41 \pm 2.32$ & $33.71 \pm 4.07$ \\
\cline { 2 - 6 } & F & $112.87 \pm 5.27$ & $138.91 \pm 7.60$ & $54.6 \pm 6.37$ & $30.21 \pm 2.29$ \\
\hline Fresh palm oil & M & $168.86 \pm 3.8^{\mathrm{a}}$ & $179.97 \pm 4.15^{\mathrm{b}}$ & $90.67 \pm 6.23^{\mathrm{a}}$ & $35.33 \pm 8.24^{\mathrm{b}}$ \\
\cline { 2 - 6 } & $\mathrm{F}$ & $150.03 \pm 3.76^{\mathrm{a}}$ & $145.64 \pm 3.18^{\mathrm{b}}$ & $76.16 \pm 4.57^{\mathrm{a}}$ & $44.84 \pm 4.23^{\mathrm{b}}$ \\
\hline Reused palm oil & $\mathrm{M}$ & $164.09 \pm 3.91^{\mathrm{a}}$ & $191.63 \pm 2.27^{\mathrm{a}}$ & $62.07 \pm 1.87^{\mathrm{b}}$ & $63.60 \pm 3.01^{\mathrm{a}}$ \\
\cline { 2 - 6 } & $\mathrm{F}$ & $148.01 \pm 3.07^{\mathrm{a}}$ & $168.33 \pm 2.21^{\mathrm{a}}$ & $48.21 \pm 6.02^{\mathrm{b}}$ & $60.81 \pm 1.07^{\mathrm{a}}$ \\
\hline Fresh sunflower oil & $\mathrm{M}$ & $147.21 \pm 2.23^{\mathrm{a}}$ & $160.74 \pm 3.2^{\mathrm{b}}$ & $56.42 \pm 4.61^{\mathrm{b}}$ & $47.44+2.23^{\mathrm{a}}$ \\
\cline { 2 - 6 } & $\mathrm{F}$ & $138.20 \pm 4.35^{\mathrm{a}}$ & $158.48 \pm 7.51^{\mathrm{b}}$ & $56.27 \pm 3.03^{\mathrm{b}}$ & $42.51 \pm 6.03^{\mathrm{a}}$ \\
\hline Reused sunflower oil & $\mathrm{M}$ & $161.37 \pm 2.02^{\mathrm{a}}$ & $216.77 \pm 3.54^{\mathrm{a}}$ & $63.01+5.20^{\mathrm{b}}$ & $56.20 \pm 6.24^{\mathrm{a}}$ \\
\cline { 2 - 6 } & $\mathrm{F}$ & $148.4 \pm 2.2^{\mathrm{a}}$ & $207.48 \pm 3.2^{\mathrm{a}}$ & $58.91 \pm 3.4^{\mathrm{a}}$ & $57.83 \pm 5.2^{\mathrm{a}}$ \\
\hline
\end{tabular}

Values are mean of 3 animals \pm SEM , $a=p<0.01$ vs Control, $b=p>0.01$ vs Control $a=$ Significant change in lipid level, $b=$ Not significant change in lipid level, $M$ - M ale, F- Female

Table 4: Serum enzyme levels in rats.

\begin{tabular}{|l|c|c|c|c|}
\hline Group & Sex & SGOT (U/L) & SGPT (U/L) & ALP (U/L) \\
\hline Control & M & $58.51 \pm 2 . .05$ & $65.64 \pm 12.72$ & $81.364 \pm 0.21$ \\
\cline { 2 - 5 } & F & $54.72 \pm 4.40$ & $55.68 \pm 4.6$ & $75.78 \pm 3.63$ \\
\hline Fresh palm oil & M & $66.04 \pm 15.63^{\mathrm{b}}$ & $55.61 \pm 6.10^{\mathrm{b}}$ & $81.64 \pm 4.6^{\mathrm{b}}$ \\
\cline { 2 - 5 } & $\mathrm{F}$ & $53.85 \pm 5.36^{\mathrm{b}}$ & $54.06 \pm 7.4^{\mathrm{b}}$ & $78.74 \pm 4.89^{\mathrm{b}}$ \\
\hline Reused palm oil & $\mathrm{M}$ & $92.05 \pm 10.37^{\mathrm{a}}$ & $91.69 \pm 8.46^{\mathrm{a}}$ & $104.94 \pm 3.21^{\mathrm{a}}$ \\
\cline { 2 - 5 } & $\mathrm{F}$ & $92.48 \pm 6.21^{\mathrm{a}}$ & $87.39 \pm 2.09^{\mathrm{a}}$ & $106.44 \pm 4.99^{\mathrm{a}}$ \\
\hline Fresh sunflower oil & $\mathrm{M}$ & $56.83 \pm 1.50^{\mathrm{b}}$ & $60.37 \pm 3.1^{\mathrm{b}}$ & $82.60 \pm 2.07^{\mathrm{b}}$ \\
\cline { 2 - 5 } & $\mathrm{F}$ & $62.75 \pm 2.79^{\mathrm{b}}$ & $52.17 \pm 6.1^{\mathrm{b}}$ & $82.52 \pm 2.12^{\mathrm{b}}$ \\
\hline Reused sunflower oil & $\mathrm{M}$ & $114.61 \pm 3.83^{\mathrm{a}}$ & $123.47 \pm 15.4^{\mathrm{a}}$ & $122.44 \pm 4.1^{\mathrm{a}}$ \\
\cline { 2 - 5 } & $\mathrm{F}$ & $117.8 \pm 3.3^{\mathrm{a}}$ & $86.41 \pm 5.83^{\mathrm{a}}$ & $113.23 \pm 4.3^{\mathrm{a}}$ \\
\hline
\end{tabular}

Values are mean of 3 animals $\pm S E M, a=p<0.01$ vs. Control, $b=p>0.01$ vs. control, $\mathrm{M}$ - Male, F- Female 
Figure 1: Histological examination of Liver
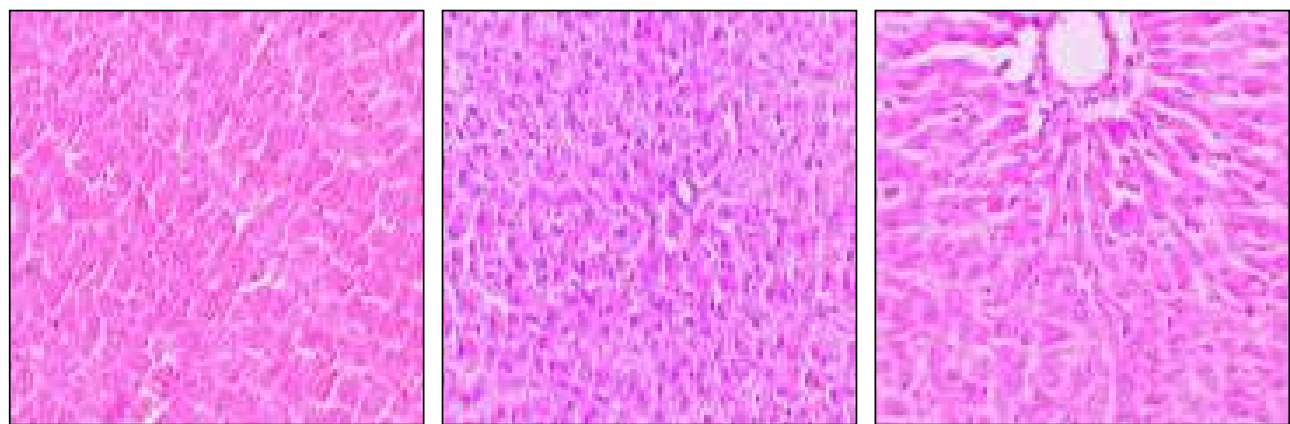

Figure 1: A. Normal, B. Recycled palm oil treated group showing swollen cell with chronic inflammatory cell infiltration, C. Recycled sunflower oil treated group showing mild central vein congestion, fine fatty vacuoles.

Figure 2: Histological examination of Heart
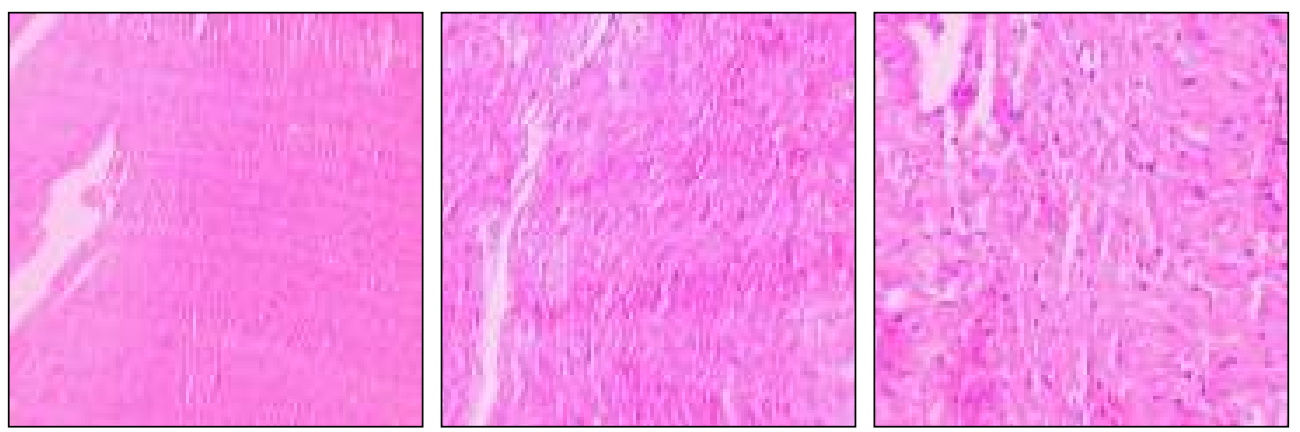

Figure 2: A. Normal, B. Recycled palm oil treated group showing congested myocardial, C. Recycled sunflower oil treated group showing papillary muscle, few vacuolation

Figure 3: Histological examination of Kidney
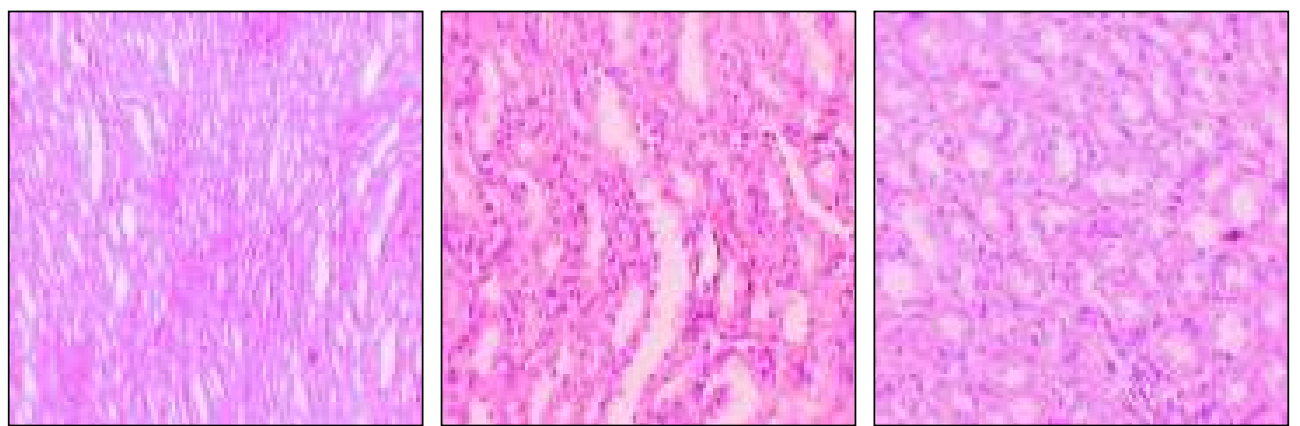

Figure 3: A. Normal, B. Recycled palm oil treated group- cells in the medullary region showing vacuoles, C. Recycled sunflower oil treated group-cells in the medullary region showing vacuoles with occasional tubule containing esinophilicmaterials.

Figure 4: Histological examination of Testis
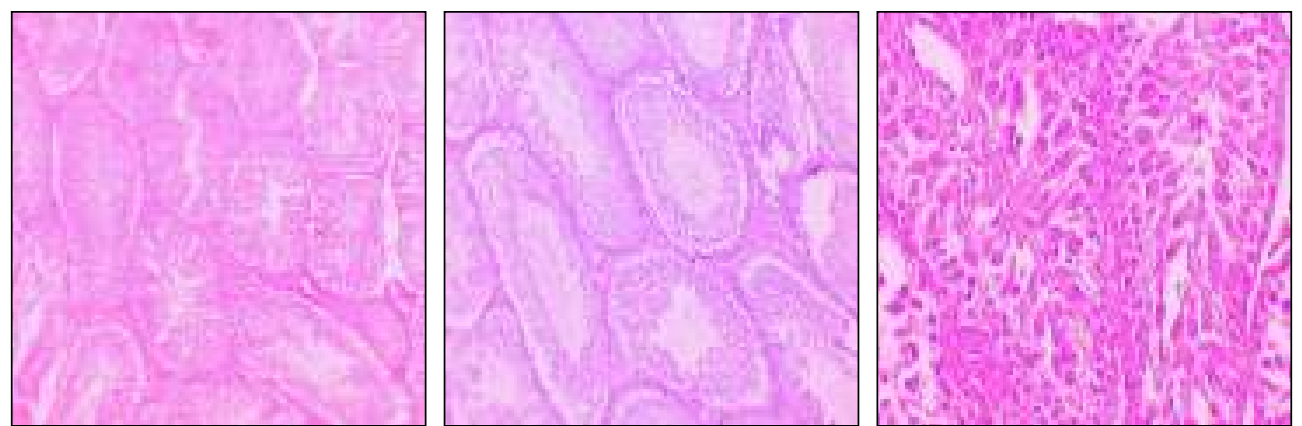

Figure 4: A. Normal, B. Recycled palm oil treated group showing fine vacuoles in cytoplasm as well as nucleus of germ cells, C. Recycled sunflower oil treated group showing vacuoles. 
alteration is likely to be associated with an enhanced cholesterol turn over, as indicated by the greater cholesterol excretion observed in the experimental group [12]. Increase in triglyceride level after oil ingestion may be due to the increase availability of substrate free fatty acids for esterification. The histopathological study supports the above findings suggesting the vital organs damage from toxic substances from the reused palm and sunflower oils. The liver cells were swollen; chronic inflammatory cells infiltration, micro granules were observed near to the portal area. The heart showed congested myocardial and few vacuolation in papillary muscle. The kidney showed tubular cell in medullary region, cytoplasmic as well as nuclear vacuoles. Occasional tubules contained eosinophilic materials in the lumen. The testis shows fine vacuoles in cytoplasm as well as nucleus of germ cells.

\section{Conclusion :}

From the present study we conclude that the process of frying gives rise to the formation of free radicals and other

\section{References:}

1. Mukherjee S, Mitra A. Health Effects of Palm Oil. J Hum Ecol 2009; 26(3): 197-203.

2. Kokate CK. Pharmacognosy, 11th edn. Nirali Prakashan, Pune. pp. 22761.

3. Quiles JL, Huertas JR, Battino M, Tortosa M C, Cassinello M , M ataix J, et al. The intake of fried virgin olive or sunflower oils differentially induces oxidative stress in rat liver microsomes. Br J Nutr 2002; 88(1): 57-65.

4. Ramachandran HD, Narasimhamurthy K, Raina PL. Effect of oxidative stress on serum and antioxidant enzymes in liver and kinder of rats and their modulation through dietary factors. Ind J Experi Biol 2002; 40: 1010-5.

5. Plummer DT. An introduction to practical Biochemistry, 3rd edn. 1971; McGraw-Hill, UK. pp. 195-9.

6. Godkar PB. Text Book of M edical Laboratory Technology, 1994; Bhalani publishing house, M umbai. pp. 118,122,140,186,203,437.

7. Henry RJ. Clinical Chemistry. Principles and Techniques, 2nd Edn. 1974; Harper and Row. pp. 822, 1974. harmful agents in the reused edible oils. These accumulative and persistent contaminants undergo biomagnifications effects. These products have unfavorable and harmful effects on the consumer's health. The study showed reused oil changes its physicochemical property like acid value, peroxide value carbonyl value and also change in body weight, serum enzyme like SGPT, SGOT, ALP and histopathological changes in experimental rats.

\section{Acknowledgements:}

The authors are thankful to the management of Nitte Education trust and NGSM Institute of Pharmaceutical Sciences, Deralakatte, Mangalore for providing the necessary facilities to carry out the study.

\section{Conflict of interest $\&$ funding:}

The authors declare that they have no conflicts of interest to disclose. This study received no specific grant from any funding agency in the public, commercial or not for profit sectors.

8. Osim E, Owu E, Isong V. Influence of chromic consumption of thermoxidized and fresh palm oil diets on basal metabolic rats, body weight and morphology of tissues in rats. Discov Innov 1994; 6: 38496.

9. Boatella RJ, Codony R, Rafecas M, Guardiala F. Recycled cooking oils: assesment of risks for public health. European parliament directorate general for research directorate, The STOA Programme 2000; PE 289.889/ Fin. St

10. DonellyJK, Robinson DS. Free radicals in foods. Free Radical Res 1995; 22: 147-76.

11. Srivastava S, Singh M, George J, Bhui K, ShuklavY. Genotoxic and carcinogenic risks associated with the consumption of repeatedly boiled sunflower oil. J Agric Food Chem 2010; 58 (20): 11179-86.

12. Aruna K, Rukkumani R, Sureshvarma P. Role of an aminothiazole derivative on ethonal and thermally oxidized sunflower oil - induced toxicity. PolishJ pharmacol 2004; 56: 233-40. 